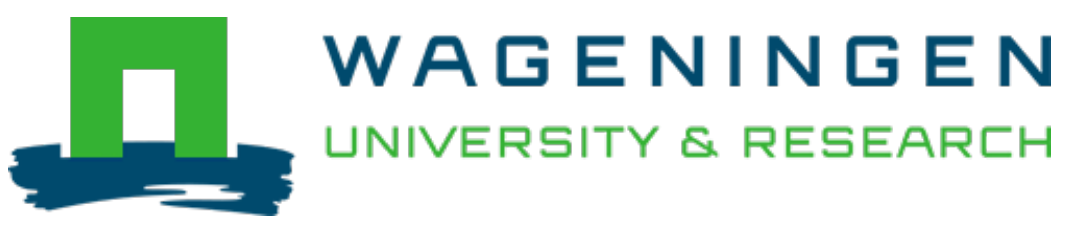

\title{
LED lighting strategies in cut flowers : Balancing plant physiology and biological control of pests
}

\author{
Acta Horticulturae \\ Dieleman, J.A.; Kruidhof, H.M.; Weerheim, K. \\ https://doi.org/10.17660/ActaHortic.2020.1296.76
}

This article is made publicly available in the institutional repository of Wageningen University and Research, under the terms of article $25 \mathrm{fa}$ of the Dutch Copyright Act, also known as the Amendment Taverne. This has been done with explicit consent by the author.

Article 25 fa states that the author of a short scientific work funded either wholly or partially by Dutch public funds is entitled to make that work publicly available for no consideration following a reasonable period of time after the work was first published, provided that clear reference is made to the source of the first publication of the work.

This publication is distributed under The Association of Universities in the Netherlands (VSNU) 'Article $25 \mathrm{fa}$ implementation' project. In this project research outputs of researchers employed by Dutch Universities that comply with the legal requirements of Article $25 \mathrm{fa}$ of the Dutch Copyright Act are distributed online and free of cost or other barriers in institutional repositories. Research outputs are distributed six months after their first online publication in the original published version and with proper attribution to the source of the original publication.

You are permitted to download and use the publication for personal purposes. All rights remain with the author(s) and / or copyright owner(s) of this work. Any use of the publication or parts of it other than authorised under article $25 \mathrm{fa}$ of the Dutch Copyright act is prohibited. Wageningen University \& Research and the author(s) of this publication shall not be held responsible or liable for any damages resulting from your (re)use of this publication.

For questions regarding the public availability of this article please contact openscience.library@,wur.nl 


\title{
LED lighting strategies in cut flowers: balancing plant physiology and biological control of pests
}

\author{
J.A. Dielemana, H.M. Kruidhof and K. Weerheim \\ Wageningen University \& Research, Business Unit Greenhouse Horticulture, Wageningen, The Netherlands.
}

\begin{abstract}
Over the last decade, LED lighting has gained considerable interest as an energy efficient light source in greenhouse horticulture. Much work on LED lighting is done under controlled conditions in the absence of sun light, whereas the primary application lies in supplementation of low light conditions in winter. A frequently forgotten aspect herein is that spectral composition may also affect the biology of pests and their natural enemies, both directly and indirectly through an impact on induced plant resistance. In this paper, we present results of trials with chrysanthemum and alstroemeria cut flowers which were exposed to lighting regimes with varying contributions of blue, green, red and far-red light. These trials were done under low levels of natural light, mimicking winter conditions. In chrysanthemum, spectra where blue or green were added did not affect stem length, plant dry weight and number of flowers when the percentage of red light remained over $75 \%$. Replacing part of the photosynthetically active radiation (PAR) light by far-red light considerably increased stem length and (in some species) plant dry weight, at the expense of flowering. In alstroemeria, the number of flowers harvested, their length and fresh weight was largest in the treatment with equal shares of blue, green, red and far-red light. In chrysanthemum, the beneficial insect Orius laevigatus was introduced and its egglaying activity and population development under different lighting strategies was monitored. The number of eggs laid by the first Orius generation was affected by the percentage red light in the spectrum, with the lowest egg number found in plants grown under $95 \%$ red. The results for egg-laying by the second Orius generation differed among chrysanthemum cultivars. The implications of this work on lighting strategies for greenhouse horticulture are discussed, both in spectral composition and in timing during the day and the season.
\end{abstract}

Keywords: chrysanthemum, alstroemeria, spectral composition, natural enemies, Orius laevigatus

\section{INTRODUCTION}

\section{Effects of LED lighting on greenhouse crops}

Among the environmental factors in horticulture, light is one of the most important variables affecting plant development, growth and production (Kendrick and Kronenberg, 1994). In northern latitudes, solar light levels during the winter can be insufficient to maintain production levels and product quality, due to the low light intensities and short photoperiods (Davis and Burns, 2016). Therefore, natural light is supplemented by supplemental lighting, with high pressure sodium (HPS) fixtures currently being the predominant greenhouse lighting source. However, the introduction of LED lighting systems has received considerable attention over the last decade. The energy efficiency of current LEDs is higher than HPS lamps, so that they can be used in the design of greenhouse systems with reduced carbon footprint (Dieleman et al., 2016). Other advantages of LEDs are that they can be positioned close to or within the canopy due to their low heat emission, and that they can emit narrow-bandwidth light allowing the design and optimization of a dedicated light spectrum for plant growth and

aE-mail: anja.dieleman@wur.nl 
development (Morrow, 2008). However, before the full potential of LEDs as a supplemental light source for plant production in greenhouses can be used, plant responses to spectral composition of the light have to be established.

In most commercially used light sources for protected cultivation of plants, the basic colour is red light, partly because red light is considered to be the most efficient photosynthetically active light, at least on an instantaneous basis (McCree, 1972; Inada, 1976). Some blue light (ranging from 5 to $10 \%$ ) is typically added to prevent excessive stem elongation (Hernandez and Kubota, 2016). Different areas of photosynthetically active radiation (PAR) between 400 and $700 \mathrm{~nm}$ and some wavelengths just outside of PAR, are perceived by plants through photoreceptors that promote specific developmental processes. This light-driven process is called photomorphogenesis and can alter plant morphology and architecture and complex processes like flowering. The commonly known influences of blue light on plant morphology are the inhibition of internode length, resulting in a more compact plant (cf. Hogewoning et al., 2010) and reduced leaf area, resulting in a lower crop light absorption that may negatively affect plant biomass (Bugbee, 2016). Wang et al. (2016) showed that leaf photosynthetic capacity (Amax) and instantaneous rate of photosynthesis $(\mathrm{Pn})$ increased with decreasing red to blue ratios until 1, associated with increased stomatal conductance. Effects of red light are perceived via the red to far red ratio. A low red to far red ratio inhibits branching and suppresses bud outgrowth (Finlayson et al., 2010). Green light is found to affect leaf morphology and orientation (Dieleman et al., 2019), so that the light can penetrate more deeply into the crop, and ultimately, increase photosynthesis and light utilization in lower leaf layers (Smith et al., 2017). Indeed, Kaiser et al. (2019b) reported an increase in tomato biomass with increasing percentages of green light up to $39 \%$. However, other studies reported no or inconclusive results on the effects of green light (Poel and Runkle, 2017; Hernandez and Kubota, 2016).

Most of the studies mentioned in the previous paragraph investigated the effects of spectral composition when LEDs were used as the sole source of lighting. However, the main application of LED lighting in protected cultivation is the supplementation of sun light under low-light conditions in the greenhouse. However, due to the limited natural day length in winter in North-West Europe and the commonly applied number of hours assimilation lighting per day (up to $19 \mathrm{~h}$ for tomato), the percentage of natural light in the daily light integral (DLI) is commonly only $20 \%$ in November, December and January (Figure 1). Therefore, in our research, we tested the effect of spectral composition of the light generated by LEDs, where the DLI of the LED light was approximately $80 \%$ of the total DLI. Only little research is conducted where the effect of light colours with a background of solar radiation is investigated. Hernandez and Kubota (2016) found that in cucumber transplants growth rate decreased with the increase of the percentage of blue light in the supplemental lighting, due to a reduced leaf area. Kaiser et al. (2019a) observed the same effects of an increase in percentage of blue light in a winter grown lighted tomato crop in a series of blue/red contributions. They concluded that although it is not strictly necessary to add blue light to greenhouse supplemental red light to obtain a functional crop, adding some (6-12\%) blue light is advantageous for growth and yield while adding $24 \%$ blue light is super optimal for growth. Adding green light up to a percentage of 39\% to a narrow bandwidth red and blue LED spectrum with a background of natural light in a glasshouse significantly and linearly increase plant biomass and yield (Kaiser et al., 2019b).

In photoperiodic plants, flower induction is primarily regulated by the photoperiod. However, light intensity and light quality have also been shown to influence growth and development of ornamental plants, such as chrysanthemum (Zheng and Van Labeke, 2018). Chrysanthemum is an economically important ornamental crop worldwide, which is a quantitative short-day plant that flowers at a day length of approximately $13 \mathrm{~h}$ or less. In the cut flower alstroemeria, flowering is induced by controlling the light and temperature of the plants, especially the root zone. At longer photoperiods, flower induction is stimulated, at the expense of the number of flowers and the formation of new shoots. That implies that day length is chosen in the cultivation of this crop depending on the production aim and developmental stage of the crop. In both crops, there is a clear demand for knowledge on the 
most efficient spectrum to supplement the natural light.

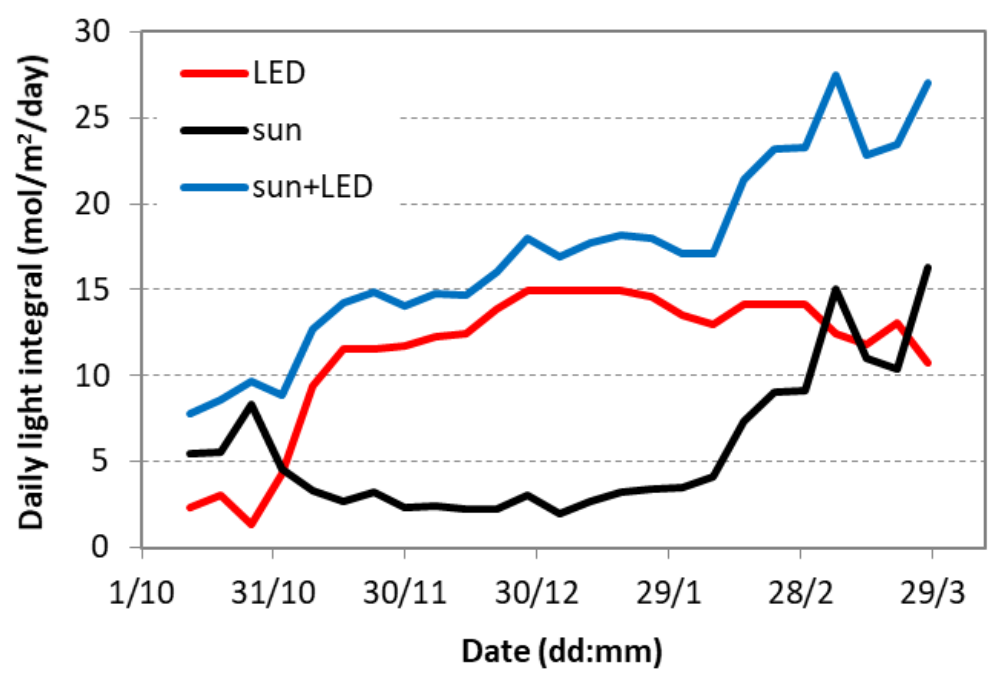

Figure 1. Pattern of the DLI (daily light integral) of LED light (LED), natural light (sun) and the sum of natural light and LED light (sun + LED) in a tomato greenhouse lighted with $206 \mu \mathrm{mol} \mathrm{m}^{-2} \mathrm{~s}^{-1} \mathrm{red} / \mathrm{blue}$ LED light with a photoperiod of $18 \mathrm{~h}$ (Dieleman et al., unpublished data). Cultivation started in October with young plants with a low assimilation capacity, therefore LED lighting in October was limited.

\section{Effects of light spectrum on arthropod pests and their natural enemies}

Just as plants, arthropods possess photoreceptors, which they use to steer important developmental and behavioural processes. Moreover, adult insects as well as the immature stages of hemimetabolous insects possess compound eyes with high spatial resolution, thus allowing for navigation and orientation. Arthropod photoreceptors typically have optima in the UV-A, green, and sometimes blue parts of the spectrum (Kelber, 2001; Warrant and Nilsson, 2006). However, arthropods do not perceive light in the red part of the spectrum, thus showing a large discrepancy with the perception and usage of light by plants.

Arthropod pests and their natural enemies have been found to be affected by light quality and quantity both directly as well as indirectly through an effect on plant-induced resistance (Vanninen et al., 2010; Johansen et al., 2011). While UV-A can have a large effect on the behaviour of both arthropod pests and some of their natural enemies (e.g., Antignus et al., 1996; Costa and Robb, 1999; Chyzik et al., 2003; Raviv and Antignus, 2004; Legarrea et al., 2010), and low to moderate UV-B doses have been shown to enhance plant induced resistance to pests (Jenkins, 2009; Ballaré, 2014; Le Gall et al., 2015; Robson et al., 2015; Escobar-Bravo et al., 2018), changes in light quality within the PAR spectrum can also affect arthropods. For example, Wang et al. (2013) found that light spectrum has a strong effect on the physiology of the Asian predatory bug Orius sauteri. Under monochromatic red light (678 $\mathrm{nm}$ ) or blue light (478 $\mathrm{nm}$ ), the developmental time of this Orius species was, respectively, 40 and 18\% lower than under white, green or yellow light. Moreover, $O$. sauteri bugs that developed under red or blue light had a lower fecundity as well as an elevated respiration quotient (red light only). Orius laevigatus, which is the Orius species that is commercially available in Europe for biological control of thrips and several other pest species, has recently been proven a valuable thrips control strategy in chrysanthemum (van Woerkom, 2019). Early introduction of $O$. laevigatus adults in chrysanthemum cuttings in combination with the application of a suitable alternative food source allowed for a relatively quick population build-up during the vegetative stages of the crop, thus ensuring timely thrips control. Because of the short cropping cycle of chrysanthemum, it is important that the population development of Orius is not constrained by unfavourable environmental conditions. We therefore monitored the egg- 
laying activity and population development of 0 . laevigatus under different LED spectra used as a supplement to low sunlight intensities.

\section{MATERIALS AND METHODS}

\section{Plant material and lighting regime}

In the Innovation and Demonstration Centre for LED lighting in greenhouse horticulture (IDC LED) in Bleiswijk, the Netherlands, chrysanthemum and alstroemeria plants were grown under six lighting treatments varying in spectral composition in September-November 2018. In one of the compartments, 14 tables of $4 \times 1.8 \mathrm{~m}$ were placed, with dynamic LED modules (Philips GreenPower LED production modules Dynamic), which allows realisation of any desired lighting regime, in time, intensity and spectral composition. These modules are tunable in blue (B; peak at $446 \mathrm{~nm}$ ), white (broad spectrum with large proportion of green (G) light with peak emission at $571 \mathrm{~nm}$ ), red (R; $660 \mathrm{~nm}$ ) and far red (FR; $730 \mathrm{~nm}$ ). The incidence of sunlight can be controlled by the use of an energy screen (LS Ultra) with a transmission of $38 \%$ and a blackout screen (LS Obscura). The greenhouse is air conditioned, allowing the realisation of winter conditions throughout the year. Climate is controlled by an ISII climate computer (Hoogendoorn), via one measuring box in the greenhouse. Realized climate conditions were $20.2 / 17.9^{\circ} \mathrm{C}$ (day/night air temperature), relative humidity of 75/81\% (day/night) and $\mathrm{CO}_{2}$ concentration of 829/805 ppm (day/night). Air temperatures were registered per light treatment (table) (30 MHz system, Amsterdam, The Netherlands).

On September 6, 2018, rooted chrysanthemum cuttings (Chrysanthemum morifolium Ramat.) 'Baltica', 'Pimento', 'Radost' and 'Zembla Cream' (Deliflor, The Netherlands) were planted in boxes $(0.2 \times 1 \mathrm{~m})$ containing a commercial peat-based potting compost on 6 tables at a density of 50 plants $\mathrm{m}^{-2}$. On September 7, 2018, alstroemeria 'Noize' (Hilverda Kooij, The Netherlands) in pots were placed on 6 other tables. Plants were irrigated with ebb and flood irrigation.

Chrysanthemum and alstroemeria plants were placed under 6 lighting strategies: 1) RB: 95\% R, 5\% B; 2) RhB: 75\% R, 25\% B; 3) RGB: 75\% R, 10\% B, 15\% G; 4) RGBFR: 75\% R, 10\% B, $5 \%$ G, $10 \%$ FR; 5) white: $35 \%$ R, 30\% B, 35\% G; and 6) whiteFR: $26 \%$ R, $22 \%$ B, $26 \%$ G, $26 \%$ FR. In chrysanthemum, light intensity during the long day period (LD) was $155 \mu \mathrm{mol} \mathrm{m}^{-2}$ $\mathrm{s}^{-1}$ at $50 \mathrm{~cm}$ height and day length was $21 \mathrm{~h}$ during the first 14 days. During the short day period (SD) the light intensity was $201 \mu \mathrm{mol} \mathrm{m}^{-2} \mathrm{~s}^{-1}$ at $80 \mathrm{~cm}$ height and day length was 11:40 $\mathrm{h}$ to initiate flowering. For alstroemeria, light intensity was $201 \mu \mathrm{mol} \mathrm{m}^{-2} \mathrm{~s}^{-1}$ at $80 \mathrm{~cm}$ height, day length was $16 \mathrm{~h}$. Spectral composition of the light was verified with a spectroradiometer (Specbos 1211UV, Jeti, Jena, Germany). To prevent light pollution between treatments, tables were separated by white plastic sheets.

Chrysanthemum plants were harvested when approximately half of the plants was flowering, having at least 3 open flowers. At the moment of harvest, 20 plants per table were harvested destructively. Shoot length, number of flowers, leaf area, number of internodes and fresh and dry weights of leaves, flowers and stems were quantified. During cultivation, alstroemeria flower stalks were harvested when one or more flowers started to open. The number of flowers per plant, stem length, average fresh weight and total fresh weight of the harvested flowers was recorded, as well as the leaf quality in three categories, namely good leaves without damage, leaves with edge necrosis (tipburn) or yellow leaves.

\section{Orius predatory bugs}

Orius laevigatus (purchased from Koppert Biological Systems, Berkel en Rodenrijs, The Netherlands) was introduced on September 13, one week after planting of the rooted chrysanthemum cuttings. On 8 release points that were equally divided over each table, 300 . laevigatus individuals of mixed sex were released (corresponding to 240 individuals per table, and approximately 160 . laevigatus females $\mathrm{m}^{-2}$ ). On the same day, decapsulated cysts of the brine shrimp, Artemia franciscana (purchased from Biobee Biological Systems, Sde Eliyaho, Israel) were sprayed over the crop as an alternative food source for Orius $\left(0.38 \mathrm{~g} \mathrm{~m}^{-2}\right)$. The addition of Artemia was repeated on September 21, October 4 and 18. On October 4 (first 
evaluation; 3.5 weeks after Orius introduction) and November 1 (second evaluation; 7 weeks after Orius introduction), 8 'Baltica' and 8 'Zembla' plants were harvested from each of the tables with the RB, RhB, RGB and white LED treatments. To prevent a bias in the selection of plants for the evaluation of Orius egg-laying, 4 groups of two adjacent plants per cultivar were harvested on different positions on each table, and the position of harvested plants was kept fixed in between the different light treatments. On each plant, both the number of open and closed Orius eggs per plant were counted. The number of open eggs corresponds to eggs from which the Orius nymph has already emerged and the number of closed eggs corresponds to the unhatched eggs that have been laid over the period of approximately one week prior to the evaluation (the developmental time from egg-nymph is on average 7.4 days at $20^{\circ} \mathrm{C}$ (Sanchez et al., 2002). During the second evaluation, the number of closed Orius eggs was markedly higher than the number of open Orius eggs. The second evaluation took place 7 weeks after the introduction of Orius adults, which corresponded with the expected timing of a new generation of fecund Orius females (egg-adult developmental time is approximately 34.6 days and adult pre-oviposition period is approximately 12.8 days at $20^{\circ} \mathrm{C}$ according to the study of Sanchez et al., (2002), corresponding to a total period of 6.8 weeks). Therefore, we divided the data set in two parts: egg-laying by the first Orius generation (total number of eggs at the first evaluation and number of open eggs at the second evaluation) and egg-laying by the second Orius generation (number of closed eggs at the second evaluation). For the data analysis, 0 . laevigatus egg numbers per plant were first averaged per group of two adjacent plants, thus resulting in 4 (pseudo)replicates per combination of light treatment and cultivar for each evaluation date. Data were subsequently square-root transformed to ensure a normal error distribution, and analysed using a linear model in $\mathrm{R}$, with light treatment, cultivar and evaluation date as the explanatory factors for the number of eggs per plant laid by the first Orius generation, and light treatment and cultivar as the explanatory factors for the number of eggs per plant laid by the second Orius generation. Based on the study of Wang et al. (2013), we hypothesized that Orius egg-laying would be reduced under LED treatments with high proportions of red light. We conducted the same statistical analyses replacing light treatment as a factor by light treatments as a quantitative variable expressed as the percentage of red light in the LED spectrum.

\section{RESULTS AND DISCUSSION}

\section{Light conditions}

During the trial, the chrysanthemum plants received a DLI of light from the sun and the LEDs of $14 \mathrm{~mol} \mathrm{~m}^{-2} \mathrm{~d}^{-1}$ in the vegetative phase, where day length was $21 \mathrm{~h}$, and $10 \mathrm{~mol} \mathrm{~m}^{-2} \mathrm{~d}^{-1}$ in the generative phase (short days). The contribution of the LED light to the total DLI the plants received was $80 \%$, the contribution of the sun light $20 \%$.

\section{Crop growth and development}

Spectral composition of the light affected stem length in chrysanthemum. Increasing the percentage of blue light $(\mathrm{RhB})$ reduced the stem length in all cultivars (Figure 2A), which is in agreement with the general response of plant height on an increasing percentage of blue light (Ouzounis et al., 2014; Hernandez and Kubota, 2016). Adding green light to the red/blue spectrum did not affect stem length. When plants were grown under a white light spectrum (blue/green/red, 30/35/35\%), stem length increased in the cultivars 'Radost' and 'Zembla' compared to the RB spectrum, which might be the effect of the high contribution of green light (Smith et al., 2017). When far-red light was added to the RGB spectrum, stem length increased by 15 to $20 \mathrm{~cm}$, depending on the cultivar. When far-red light was added to the white light, stem length increased by 35 to $60 \mathrm{~cm}$. Comparable results were found in a number of ornamental species that were taller in a blue light deficient environment and shorter in a far red deficient environment compared to the reference situation of sunlight and HPS (Runkle and Heins, 2001). Stem elongation was primarily due to the increase in internode length, which was $20 \%$ greater averaged over all cultivars for RGB FR compared to RGB and 55\% for white FR compared to white. 

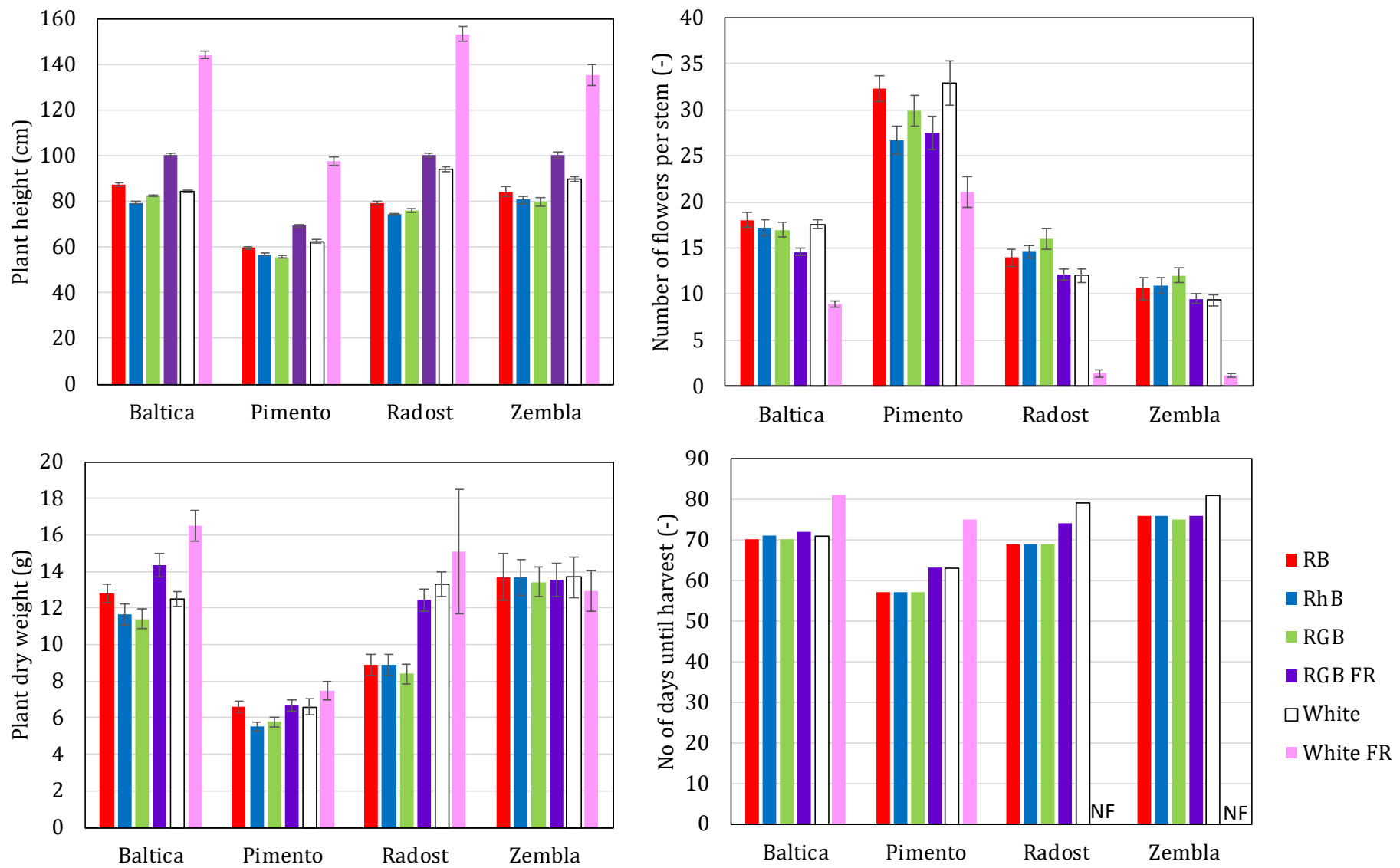

Figure 2. Effect of the spectral composition of the supplemental light on stem length (A), plant dry weight (B) and number of flowers per stem (C) of chrysanthemum 'Baltica,' 'Pimento', 'Radost' and 'Zembla' at the final destructive harvest which took place when at least $50 \%$ of the plants of that cultivar and treatment had at least 3 open flowers; and the number of days from planting until final destructive harvest (D). Treatments are 1) RB: 95\% R, 5\% B; 2) RhB: 75\% R, 25\% B; 3) RGB: 75\% R, 10\% B, 15\% G; 4) RGBFR: 75\% R, 10\% B, $5 \%$ G, 10\% FR; 5) white: 35\% R, 30\% B, 35\% G; and 6) whiteFR: 26\% R, 22\% B, 26\% G, 26\% FR. Vertical bars indicate the standard error of mean $(n=20)$. NF indicates non flowering. 
Interestingly, large differences in the response of the biomass formed under the different lighting strategies were observed between cultivars. Where aboveground biomass was largely affected by the treatments in 'Baltica' and 'Radost', the shoot biomass of 'Zembla' was comparable between all treatments. Shoot biomass of the treatments RB, RhB and RGB were comparable in all cultivars (Figure $2 \mathrm{~B}$ ) which agrees with the results of Zheng and Van Labeke (2018) who did not find an effect of R, B, and R/B (75/25\%) or white light on shoot dry weight. White light only increased shoot dry weight (by 50\%) in 'Radost'. A partial replacement of PAR light with far red light increased shoot dry weight in 'Baltica' and 'Radost' (Figure 2B). The increased biomass at lower PAR levels seems counterintuitive. However, plants grown under spectra with far red were taller than in LED spectra without far red. This implies that they reached the lamps sooner, and thereby received a higher light intensity. Furthermore, far-red light was found to increase the photosynthetic efficiency of shorter wavelength light that over-excites PSII (Zhen and van Iersel, 2017). The combination of these two factors may explain the higher plant biomass under spectra where far red light has partially replaced the PAR light.

The number of flowers per stem was only marginally affected in 'Baltica', 'Radost' and 'Zembla', although in all cultivars the number of flowers was considerably reduced in the treatment white light with far red (Figure 2C). In general, far-red light promotes flowering in long-day ornamental species as was shown in research with spectral filters (Runkle and Heins, 2001) and LED lighting (Davis and Burns, 2016). However, this response might be different in a short-day plant such as chrysanthemum. In the genotypes 'Radost' and 'Zembla', we observed some flowers per stem, but the treatments did not meet the standard of at least three open stems per flower shoot. Therefore, in Figure 2D these treatments were recorded as 'nonflowering' (NF). The number of days between start of the generative phase (short days) and flowering was comparable between the treatments RB, RhB and RGB. The number days until harvest increased when far-red light was added to the RGB treatment, ranging from 1 to 4 days.

During the cultivation of the alstroemeria plants under the different light spectra, flowers were harvested when one or more flowers started to open. The number of harvested flowers increased from approximately 4 flowers per plant for RB, RhB, RGB and RGBFR to 7 flowers per plant for the spectrum with white and far-red light. White light only reduced the number of harvested flowers to 3 (Figure 3B). The length of the harvested flower stalks slightly decreased at an increasing percentage blue light (RhB vs. RB), which is in agreement with the general response of increased percentages of blue light (Davis and Burns, 2016). Remarkably, the length of the flowers did not increase when far-red light was added to the RGB spectrum, whereas the length of the flowers increased by $35 \mathrm{~cm}$ when part of the white light was replaced by far-red light (whiteFR). This resulted in an increase in fresh weight of the harvested flowers, which was also higher in the treatment whiteFR. The increase in number of harvested shoots and the higher average flower weight led to a doubling of the total fresh weight of the harvested flowers in the treatment white FR compared to the RB light treatment. However, the leaf quality was less for this treatment. Since leaf quality is an important ornamental trait for ornamentals, this should be taken into account when making the choice for spectrum to be applied. 

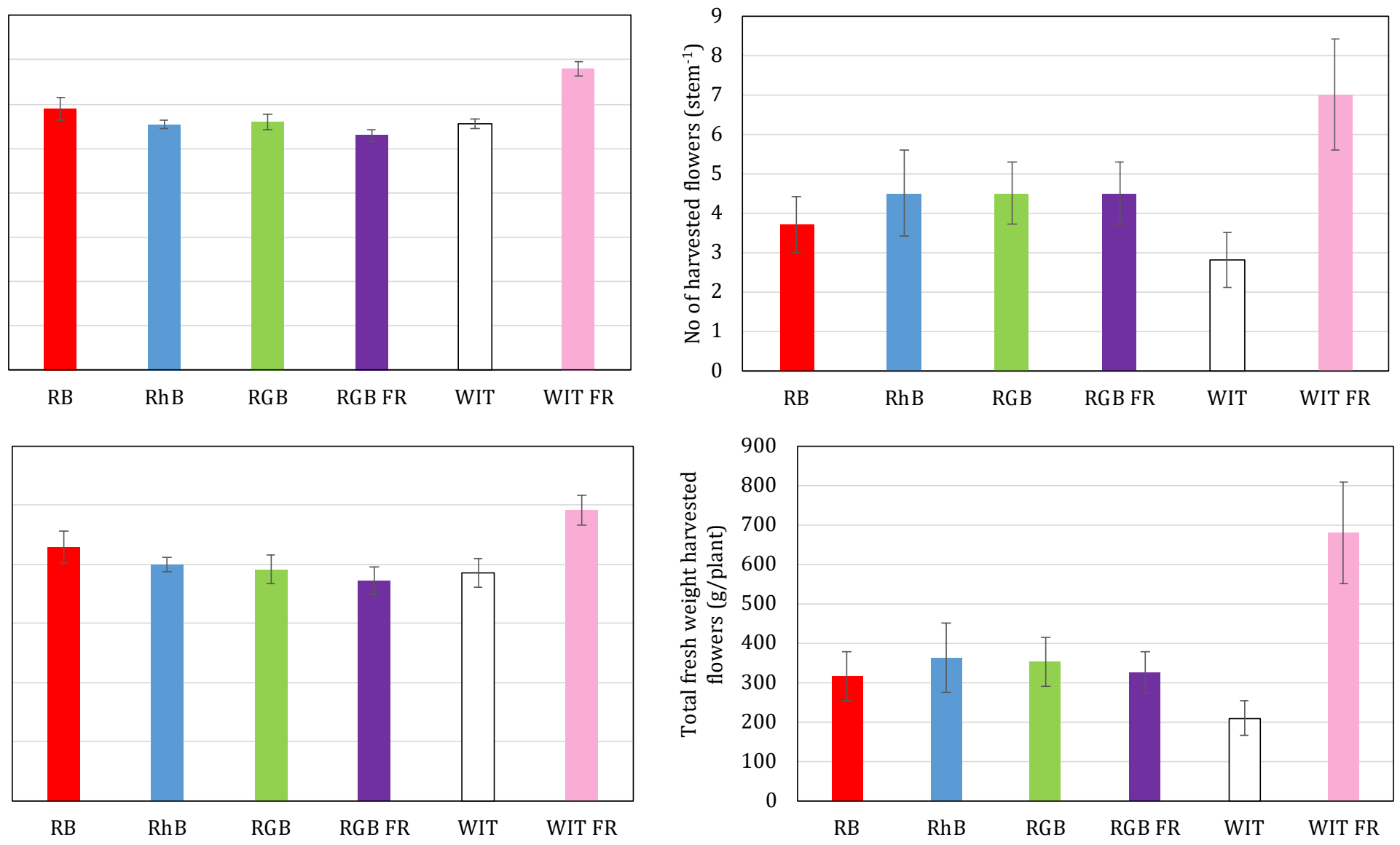

Figure 3. Effect of the spectral composition of the supplemental light on the length of the harvested flower stalks (A), number of harvested flowers (B), flower fresh weight and the total fresh weight of the harvested number of flowers (D) of alstroemeria 'Noize'. Treatments are 1) RB: $95 \%$ R, 5\%B; 2) RhB: 75\% R, 25\% B; 3) RGB: 75\% R, 10\% B, 15\% G; 4) RGBFR: 75\% R, 10\% B, 5\% G, 10\% FR; 5) white: $35 \%$ R, 30\% B, 35\% G; and 6) whiteFR: 26\% R, 22\% B, 26\% G, 26\% FR. Vertical bars indicate the standard error of mean (n=6). 


\section{Orius predatory bugs}

During the first evaluation, 3.5 weeks after the introduction of 0 . laevigatus adults into the plots, we counted an average of 14-15 'total' (open + closed) eggs per plant in the white and $\mathrm{RhB}$ treatments, 10 total eggs per plant in the RGB treatment and 6 total eggs per plant in the RB treatment (Figure 4). At the second evaluation (7 weeks after the Orius introduction), the number of open (= hatched) eggs was only slightly higher in most of the light treatments (20, 12, 10 and 16 eggs plant ${ }^{-1}$, respectively, in the white, RB, RhB and RGB treatments), indicating that most eggs were laid in the first month following Orius introduction). With a planting density of 50 plants $\mathrm{m}^{-2}$, and an initial density of approximately 16 Orius females $\mathrm{m}^{-2}$, Orius produced on average approximately 63 eggs female-1 in the white LED treatment and 38 eggs female ${ }^{-1}$ in the RB treatment. Due to the large in-between plant variation in the number of Orius eggs, the effect of LED treatment on the total eggs produced by the first Orius generation was not or marginally significant $(\mathrm{P}=0.084)$. However, when using percentage of red light within the LED spectrum as a quantitative explanatory variable (white $=35 \%$ red, $\mathrm{RB}=95 \%$ red, $\mathrm{RhB}=75 \%$ red and $\mathrm{RGB}=75 \%$ red), we did find a significant effect of LED treatment $(\mathrm{P}=0.01)$. The effect of light treatment on Orius egg numbers was independent from chrysanthemum cultivar $(\mathrm{P}=0.23)$ and there was also no significant main effect of cultivar $(\mathrm{P}=0.10)$ on Orius egg deposition.
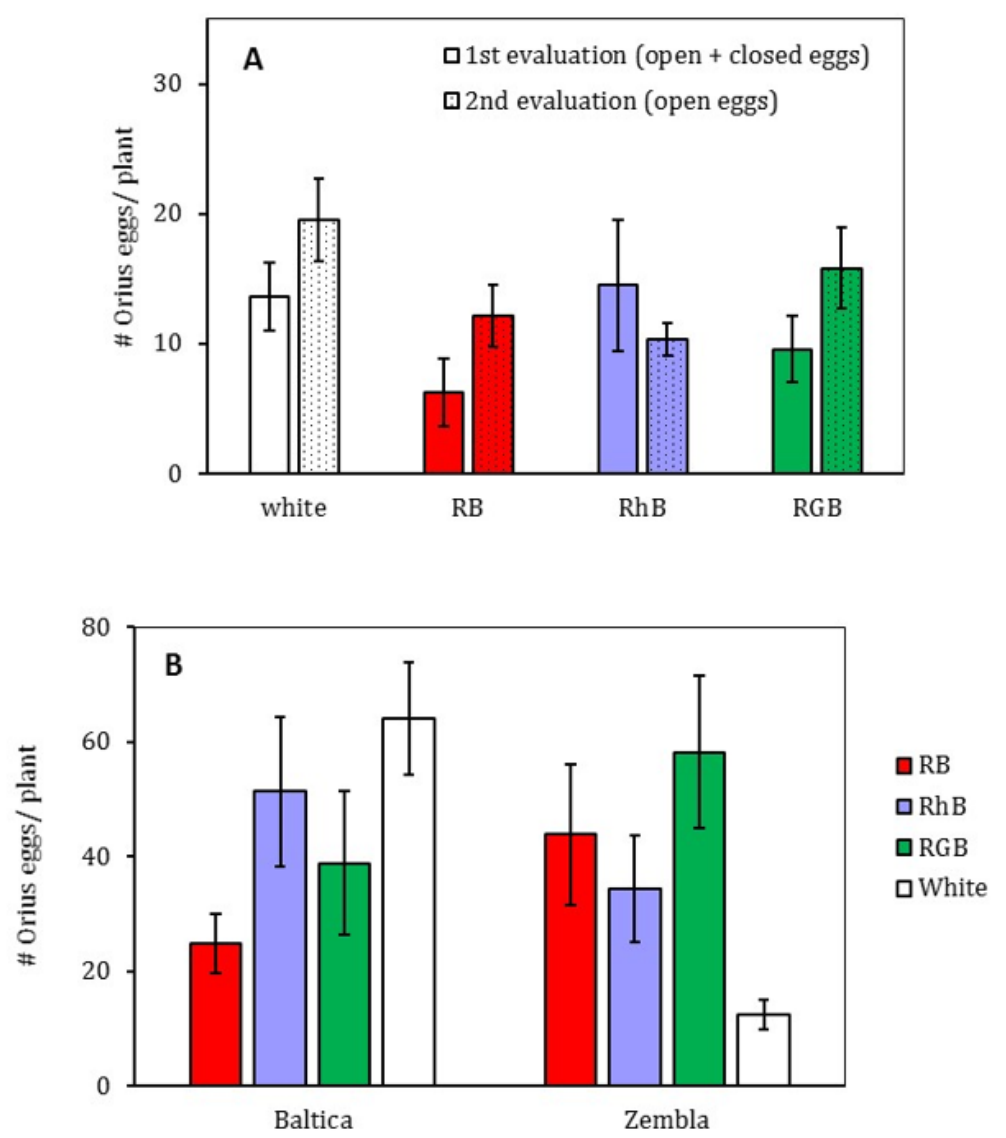

Figure 4. Effect of the spectral composition of the supplemental light on the number of open and closed eggs of Orius laevigatus of the first generation (A) and the second generation (B), for chrysanthemum 'Baltica' and 'Zembla'. Treatments are 1) RB: 95\% R, 5\% B; 2) RhB: 75\% R, 25\% B; 3) RGB: 75\% R, 10\% B, 15\% G; and 4) white: $35 \%$ R, 30\% B, 35\% G. Vertical bars indicate the standard error of mean $(n=4)$. 
The average number of closed eggs at the second evaluation (7 weeks after the Orius introduction), representing the initial egg production over a period of maximum one week of the second Orius generation, was 2-4 times as high as the average number of eggs laid by the first Orius generation, indicating a steep increase in population size in all the LED treatments. However, in contrast to the egg deposition by the first Orius generation, this time there was a significant interaction between percentage of red light within the LED spectrum and chrysanthemum cultivar. When analysing the number of Orius eggs plant ${ }^{-1}$ separately for each cultivar, a lower percentage of red in the LED spectrum resulted in a higher number of Orius eggs plant ${ }^{-1}$ in the 'Baltica' cultivar $(\mathrm{P}=0.035)$ (as was found for the first Orius generation), but in a higher number of Orius eggs in the 'Zembla' cultivar ( $\mathrm{P}=0.025)$. Whereas plants were still in the vegetative state during the egg-laying period of the first Orius generation, the plants had entered the generative stage at the time of the second evaluation, when the initial egg deposition of the second Orius generation was assessed. Data on plant measurements showed that time to flowering in 'Baltica' was not affected by LED treatment, whereas it was delayed under the white LED spectrum in 'Zembla' compared to the RB, RhB and RGB spectra. Although we have not recorded in which plant tissues the Orius eggs were deposited, it is known that Orius has a preference for egg deposition in newly formed soft plant tissues (G. Messelink, pers. commun.). It has been observed in other greenhouse ornamentals, such as gerbera, alstroemeria and rose, that Orius has a preference to deposit its eggs in the petals of flower (buds). We therefore hypothesize that the cultivar-dependent effect of LED spectrum on egg laying of the second Orius generation may be related to a cultivar-dependent influence of LED spectrum on flower induction.

\section{Development of sustainable production system based on led lighting}

For protected cultivation, there are two distinct production systems: 1) greenhouses, where natural light is present and can be supplemented by (LED) lighting, and 2) day light less cultivation systems, which can be named vertical farms, controlled environment agriculture etc., but all have the characteristic that light is only provided by electric light sources in the system. Most of the research executed on the effects of spectral composition of the light on plants was done in climate chambers, i.e. in the absence of natural light. In this study we focus on the effects of spectral composition of the assimilation light that was used to supplement the natural sunlight. A complication in explaining the results of these treatments is the spectrum that is realised during the day and the experiment. The spectrum the plants receive is a combination of the spectrum of the lamps and the spectrum of the sunlight over the day, where intensities of supplemental light and sunlight should be taken into account. Since the intensity of the sunlight continuously changes, both the light intensity and its spectral composition are variable. So far, there is no system developed that accurately describes a system like this. Elements should be at least the spectrum of the lamps, intensity of the light plants received from the lamps and the sun, photoperiod of the lamps and the natural light, maximum intensity of natural light. It is recommended that a design for this system should be made, so that it can be used by researchers and growers to describe the light climate for the plants in a uniform way and compare trials.

In our research, we used supplemental LED lighting with a continuous spectrum during the day. However, this generates two distinct spectra for the plants: the LED spectrum without natural sunlight, and the combined LED and sunlight spectrum when there is natural sunlight. To which extent the "night time" spectrum or the "day time" spectrum primarily determines the effects on plant growth and development remains to be established. LED lighting enables dynamic lighting recipes where light intensity and spectrum can be controlled during the day. Ideally, this could be implemented in a greenhouse control strategy, based on automated measurements of light spectrum and intensity with a spectroradiometer. Furthermore, during the course of plant development, specific plant processes could be steered by spectral composition of the light, such as stem elongation and leaf size, thereby affecting light interception, flowering, fruit set and fruit quality.

The observed effects of LED spectral composition on the population development of Orius laevigatus in the two cultivars 'Zembla' and 'Baltica' need to be confirmed by an 
additional experiment, as only one real replicate per light treatment was included. Moreover, (plant-mediated) effects of LED spectrum on pests, diseases and other natural enemies also need further investigation. Knowledge on the effect of LED spectra on biological pest and disease control can be integrated into an integrated pest management approach in several ways. At the one hand, the introduction schemes of natural enemies could be adapted to (partially) compensate for any negative side-effects of the lighting strategy that is optimal for crop growth and development. Moreover, when any negative side-effects of a LED strategy that is optimal for the crop on pests and diseases are detected, compensatory alternative ways to induce crop resistance may be identified. Finally, a lighting strategy that is suitable for crop growth and development could be tweeked such that negative side-effects on biological pest and disease control are minimized. This may also include the addition of parts of the light spectrum that do not support crop growth, such as small doses of UV-B light that have been shown to induce plant resistance against pests (Jenkins, 2009; Ballaré, 2014; Le Gall et al., 2015; Robson et al., 2015; Escobar-Bravo et al., 2018).

Over the last decade, the use of LED lighting as a source of assimilation lighting in greenhouse horticulture has gained considerable interest. Furthermore, an increasing number of commercial greenhouses have implemented LEDs as their sole source of lighting. However, much research is still required to determine optimal LED spectra for the different crops in which LED lighting is applied. Our study has already shown that, in contrast to tomato which grows well under red/blue LED lighting (Dieleman et al., 2016), other crops may have very different demands with respect to the light spectrum. In designing lighting strategies, the most crucial processes per crop should be established. An example is that for alstroemeria, in the semi-commercial trial that was based on our results, a light spectrum was chosen with $70 \%$ red light and approximately equal contributions of blue, green and far red light. In the choice for this spectrum, the effects of light spectrum on leaf quality outweighed the effects on number of flowers produced. As energy-efficient light sources, LEDs can contribute to sustainable production systems for greenhouse horticulture. How the LEDs will be applied, will differ per crop and cultivation system.

\section{ACKNOWLEDGEMENTS}

This research was funded by the Ministry of Agriculture, Nature and Food Quality and Glastuinbouw Nederland within the framework of the programme "Greenhouse as a source of energy"). The IDC LED is a joint facility of Wageningen University and Research and Signify, who provided the dynamic LED modules and the control system. Chrysanthemum plants were kindly provided by the chrysanthemum breeder Deliflor (Maasdijk, The Netherlands) and the alstroemeria plants by Hilverda Kooij (De Kwakel, The Netherlands).

\section{Literature cited}

Antignus, Y., Mor, N., Joseph, R.B., Lapidot, M., and Cohen, S. (1996). Ultraviolet-absorbing plastic sheets protect crops from insect pests and from virus diseases vectored by insects. Environ. Entomol. 25 (5), 919-924 https://doi.org/10.1093/ee/25.5.919.

Ballaré, C.L. (2014). Light regulation of plant defense. Annu Rev Plant Biol 65 (1), 335-363 https://doi.org/ 10.1146/annurev-arplant-050213-040145. PubMed

Bugbee, B. (2016). Towards an optimal spectral quality for plant growth and development: the importance of radiation capture. Acta Hortic. 1134, 1-12 https://doi.org/10.17660/ActaHortic.2016.1134.1.

Chyzik, R., Dobrinin, S., and Antignus, Y. (2003). Effect of a UV-deficient environment on the biology and flight activity of Myzus persicae and its hymenopterous parasite Aphidius matricariae. Phytopar. 31 (5), 467-477 https://doi.org/10.1007/BF02979740.

Costa, H.S., and Robb, K.L. (1999). Effects of ultraviolet-absorbing greenhouse plastic films on flight behavior of Bemisia argentifolii (Homoptera: Aleyrodidae) and Frankliniella occidentalis (Thysanoptera: Thripidae). J. Econ. Entomol. 92 (3), 557-562 https://doi.org/10.1093/jee/92.3.557.

Davis, P.A., and Burns, C. (2016). Photobiology in protected horticulture. Food Energy Secur. 5 (4), 223-238 https://doi.org/10.1002/fes3.97.

Dieleman, J.A., De Visser, P.H.B., and Vermeulen, P.C.M. (2016). Reducing the carbon footprint of greenhouse grown 
crops: re-designing LED-based production systems. Acta Hortic. 1134, 395-402 https://doi.org/10.17660/ ActaHortic.2016.1134.51.

Dieleman, J.A., De Visser, P.H.B., Meinen, E., Grit, J.G., and Dueck, T.A. (2019). Integrating morphological and physiological responses of tomato plants to light quality to the crop level by 3D modeling. Front Plant Sci 10, 839 https://doi.org/10.3389/fpls.2019.00839. PubMed

Escobar-Bravo, R., Ruijgrok, J., Kim, H.K., Grosser, K., Van Dam, N.M., Klinkhamer, P.G.L., and Leiss, K.A. (2018). Light intensity-mediated induction of trichome-associated allelochemicals increases resistance against thrips in tomato. Plant Cell Physiol. 59 (12), 2462-2475 https://doi.org/10.1093/pcp/pcy166. PubMed

Finlayson, S.A., Krishnareddy, S.R., Kebrom, T.H., and Casal, J.J. (2010). Phytochrome regulation of branching in Arabidopsis. Plant Physiol. 152 (4), 1914-1927 https://doi.org/10.1104/pp.109.148833. PubMed

Hernandez, R., and Kubota, C. (2016). Physiological responses of cucumber seedlings under different blue and red photon flux ratios using LEDs. Environ. Exp. Bot. 121, 66-74 https://doi.org/10.1016/j.envexpbot.2015.04.001.

Hogewoning, S.W., Trouwborst, G., Maljaars, H., Poorter, H., van Ieperen, W., and Harbinson, J. (2010). Blue light dose-responses of leaf photosynthesis, morphology, and chemical composition of Cucumis sativus grown under different combinations of red and blue light. J. Exp. Bot. 61 (11), 3107-3117 https://doi.org/10.1093/jxb/erq132. PubMed

Inada, K. (1976). Action spectra for photosynthesis in higher plants. Plant Cell Physiol. 17, 355-365 https://doi.org/10.1093/oxfordjournals.pcp.a075288.

Jenkins, G.I. (2009). Signal transduction in responses to UV-B radiation. Annu Rev Plant Biol 60 (1), 407-431 https://doi.org/10.1146/annurev.arplant.59.032607.092953. PubMed

Johansen, N.S., Vanninen, I., Pinto, D.M., Nissinen, A.I., and Shipp, L. (2011). In the light of new greenhouse technologies: 2. Direct effects of artificial lighting on arthropods and integrated pest management in greenhouse crops. Ann. Appl. Biol. 159 (1), 1-27 https://doi.org/10.1111/j.1744-7348.2011.00483.x.

Kaiser, E., Ouzounis, T., Giday, H., Schipper, R., Heuvelink, E., and Marcelis, L.F.M. (2019a). Adding blue to red supplemental light increases biomass and yield of greenhouse-grown tomatoes, but only to an optimum. Front Plant Sci 9, 2002 https://doi.org/10.3389/fpls.2018.02002. PubMed

Kaiser, E., Weerheim, K., Schipper, R., and Dieleman, J.A. (2019b). Partial replacement of red and blue by green light increases biomass and yield in tomato. Sci. Hortic. (Amsterdam) 249, 271-279 https://doi.org/10.1016/j.scienta. 2019.02.005.

Kelber, A. (2001). Receptor based models for spontaneous colour choices in flies and butterflies. Entomol. Exp. Appl. 99 (2), 231-244 https://doi.org/10.1046/j.1570-7458.2001.00822.x.

Kendrick, R.E., and Kronenberg, G.H.M. (1994). Photomorphogenesis in Plants (Dordrecht, The Netherlands: Springer Science+Business Media), pp.828.

Le Gall, H., Philippe, F., Domon, J.M., Gillet, F., Pelloux, J., and Rayon, C. (2015). Cell wall metabolism in response to abiotic stress. Plants (Basel) 4 (1), 112-166 https://doi.org/10.3390/plants4010112. PubMed

Legarrea, S., Karnieli, A., Fereres, A., and Weintraub, P.G. (2010). Comparison of UV-absorbing nets in pepper crops: spectral properties, effects on plants and pest control. Photochem. Photobiol. 86 (2), 324-330 https://doi.org/ 10.1111/j.1751-1097.2009.00657.x. PubMed

McCree, K.J. (1972). The action spectrum, absorbance and quantum yield of photosynthesis in crop plants. Agric. Meteorol. 9, 191-216 https://doi.org/10.1016/0002-1571(71)90022-7.

Morrow, R.C. (2008). LED lighting in horticulture. HortScience 43 (7), 1947-1950 https://doi.org/10.21273/ HORTSCI.43.7.1947.

Ouzounis, T., Fretté, X., Rosenqvist, E., and Ottosen, C.O. (2014). Spectral effects of supplementary lighting on the secondary metabolites in roses, chrysanthemums, and campanulas. J. Plant Physiol. 171 (16), 1491-1499 https://doi.org/10.1016/j.jplph.2014.06.012. PubMed

Poel, B.R., and Runkle, E.S. (2017). Spectral effects of supplemental greenhouse radiation on growth and flowering of annual bedding plants and vegetable transplants. HortScience 52 (9), 1221-1228 https://doi.org/10.21273/ HORTSCI12135-17.

Raviv, M., and Antignus, Y. (2004). UV radiation effects on pathogens and insect pests of greenhouse-grown crops. Photochem. Photobiol. 79 (3), 219-226 https://doi.org/10.1562/SI-03-14.1. PubMed

Robson, T.M., Klem, K., Urban, O., and Jansen, M.A.K. (2015). Re-interpreting plant morphological responses to UVB radiation. Plant Cell Environ. 38 (5), 856-866 https://doi.org/10.1111/pce.12374. PubMed

Runkle, E.S., and Heins, R.D. (2001). Specific functions of red, far red, and blue light in flowering and stem extension of long-day plants. J. Am. Soc. Hortic. Sci. 126 (3), 275-282 https://doi.org/10.21273/JASHS.126.3.275. 
Sanchez, J.A., Sanchez, J.A., and Lacasa, A. (2002). Modelling population dynamics of Orius laevigatus and $O$. albidipennis (Hemiptera: Anthocoridae) to optimize their use as biological control agents of Frankliniella occidentalis (Thysanoptera: Thripidae). Bull. Entomol. Res. 92 (1), 77-88 https://doi.org/10.1079/BER2001136. PubMed

Smith, H.L., McAusland, L., and Murchie, E.H. (2017). Don't ignore the green light: exploring diverse roles in plant processes. J. Exp. Bot. 68 (9), 2099-2110 https://doi.org/10.1093/jxb/erx098. PubMed

van Woerkom, M. (2019). Researchers make breakthrough in thrips control in chrysanthemum. Change in thinking: start off with biological controls. Greenhouses 7 (3), 30-31.

Vanninen, I., Pinto, D.M., Nissinen, A.I., Johansen, N.S., and Shipp, L. (2010). In the light of new greenhouse technologies: 1. Plant-mediated effects of artificial lighting on arthropods and tritrophic interactions. Ann. Appl. Biol. 157 (3), 393-414 https://doi.org/10.1111/j.1744-7348.2010.00438.x.

Wang, S., Tan, X.L., Michaud, J.P., Zhang, F., and Guo, X. (2013). Light intensity and wavelength influence development, reproduction and locomotor activity in the predatory flower bug Orius sauteri (Poppius) (Hemiptera: anthocoridae). BioControl 58 (5), 667-674 https://doi.org/10.1007/s10526-013-9522-2.

Wang, J., Lu, W., Tong, Y., and Yang, Q. (2016). Leaf morphology, photosynthetic performance, chlorophyll fluorescence, stomatal development of lettuce (Lactuca sativa L.) exposed to different ratios of red light to blue light. Front Plant Sci 7, 250 https://doi.org/10.3389/fpls.2016.00250. PubMed

Warrant, E., and Nilsson, D.E. (2006). Invertebrate Vision Preface (Cambridge, UK: Cambridge University Press), p.XIX-XXI.

Zhen, S., and van Iersel, M.W. (2017). Far-red light is needed for efficient photochemistry and photosynthesis. J. Plant Physiol. 209, 115-122 https://doi.org/10.1016/j.jplph.2016.12.004. PubMed

Zheng, L., and Van Labeke, M.C. (2018). Effects of different irradiation levels of light quality of chrysanthemum. Sci. Hortic. (Amsterdam) 233, 124-131 https://doi.org/10.1016/j.scienta.2018.01.033. 
